\title{
VISÕES SOBRE O MOVIMENTO BLACK RIO: APONTAMENTOS TEÓRICOS SOBRE ESTILO, CONSUMO CULTURAL E IDENTIDADE NEGRA $^{1}$
}

\author{
VIEWS ON THE BLACK RIO MOVEMENT: THEORETICAL NOTES ON \\ STYLE, CULTURAL CONSUMPTION AND BLACK IDENTITY
}

\author{
VISIONES SOBRE EL MOVIMIENTO BLACK RIO: APUNTES TEÓRICOS \\ SOBRE ESTILO, CONSUMO CULTURAL Y IDENTIDAD NEGRA
}

\author{
Luciana Xavier de Oliveira \\ Doutoranda do Programa de Pós- \\ Graduação em Comunicação da \\ Universidade Federal Fluminense \\ luciana.ufba@gmail.com
}

\section{Resumo}

O Movimento Black Rio se tornou um fenômeno de massa no Rio de Janeiro, nos anos 70, particularmente entre uma juventude afro-brasileira dos subúrbios e bairros operários da Zona Norte. Milhares de jovens compareciam, todos os finais de semana, aos bailes black para dançar ao som de discos de soul americanos tocados por celebrados DJs. O fenômeno ganhou destaque por seu caráter de resistência cultural e afirmação de uma identidade negra, que se oporia à retórica do mito da democracia racial. Neste artigo, pretendemos aprofundar a discussão em torno de possibilidades de mobilizações? políticas em torno do consumo cultural, interessando-nos por perceber como o movimento, através do estabelecimento de redes de consumo, lazer e entretenimento, configurou-se como um novo projeto identitário, dotado de um potencial político alternativo pautado pelo estilo.

Palavras-Chave: Movimento Black Rio; consumo cultural; identidade negra; estilo.

\begin{abstract}
The Black Rio Movement became a mass phenomenon in Rio de Janeiro in the 1970s, particularly between the african-Brazilian youth workers and suburban neighborhoods of North Zone. Thousands of young people attended, every weekend, the black dances to listen to American soul music played by celebrated DJs. The phenomenon gained prominence as a phenomenon of cultural resistance and affirmation of a black identity, in opposition to the rhetoric of racial democracy. In this article, we discuss the politics of cultural consumption, trying to understand how the movement, by establishing networks of consumption, leisure and entertainment, was configured as a new identity project, charged with an alternative political potential and guided by the style.
\end{abstract}

\footnotetext{
${ }^{1}$ Uma versão anterior deste artigo foi apresentada durante o Comunicon 2014 (Congresso Internacional Comunicação e Consumo) realizado em outubro de 2014, no Grupo de Trabalho Comunicação, Discursos da Diferença e Biopolíticas do Consumo.
} 
Key words: Black Rio Movement; cultural consumption; black identity; style.

\section{Resumen}

El Movimiento Black Rio se convirtió en un fenómeno de masas en Río de Janeiro, en particular entre la juventud afrobrasileña de los barrios suburbanos de la Zona Norte. En 70 años, miles de jóvenes, todos los fines de semana, iban a los bailes black para bailar con los registros de soul estadounidense tocados por célebres DJs. El fenómeno ganó prominencia por su carácter de resistencia cultural y la afirmación de una identidad negra que se opone a la retórica del mito de la democracia racial. En este artículo, nos proponemos profundizar la discusión sobre las políticas del consumo cultural, interesante para entendermos cómo el movimiento, mediante el establecimiento de redes de consumo, de ocio y de entretenimiento se ha configurado como un nuevo proyecto de identidad, dotado de un potencial político alternativo guiado por el estilo.

Palabras clave: Movimiento Black Rio; consumo cultural; identidad negra; estilo.

Esta obra está licenciada sob uma Licença Creative Commons

\section{INTRODUÇÃO}

O soul se tornou um fenômeno de massa no Rio de Janeiro, particularmente entre uma juventude afro-brasileira dos subúrbios e bairros operários da Zona Norte. Nos anos 70, milhares de jovens compareciam, todos os finais de semana, aos bailes realizados em clubes recreativos para dançar ao som de discos de soul norte-americanos tocados por celebrados DJs. De fato, a soul music integrou uma importante parte da música brasileira da época e modificou a cena cultural carioca. Como parte das atividades de lazer dos finais de semana no subúrbio da cidade, os bailes soul geralmente eram realizados em clubes sociais recreativos e quadras de escolas de samba, cujo público principal eram grupos de trabalhadores e uma classe média negra emergente. O discurso Black Power, em particular, encontrou ali um solo fértil para se manifestar, estabelecendo uma nova agenda para o movimento negro carioca. Ao mesmo tempo, nesses bailes eram desenvolvidas estratégias alternativas para a construção de um estilo particular, por meio de diferentes exercícios identitários.

A quase totalidade dos textos jornalísticos, trabalhos acadêmicos e depoimentos públicos que abordam a memória do chamado Movimento Black Rio se debruçam sobre a temática da busca, construção e afirmação de uma identidade específica "negra", que se 
oporia intensamente à retórica do mito da democracia racial. Não raramente, é possível observar o modo como diferentes autores de áreas diversas articulam as suas investigações na abordagem do fenômeno, que giram em torno da constituição dos bailes black como espaços de novas constituições identitárias afro-brasileiras e formas de resistência (VIANNA, 1997, ESSINGER, 2005, HANCHARD, 2001, FRIAS, 1976, THAYER, 2006, GIACOMINI, 2006). Neste conjunto de textos "clássicos" que abordam a história do Movimento Black Rio, reproduz-se a ideia de que o negro brasileiro estaria em busca de uma identidade autônoma e autêntica, diante do fato de que sua cultura específica - seja o samba ou religiões de matriz africana - ter sido, não sem tensões, apropriada pelo Estado na formatação de uma identidade nacional. Assim, o também chamado movimento Black Soul seria uma resposta e reação a um suposto "assalto cultural" cometido pelo Estado e pelas elites brancas brasileiras que representava. Como solução, seus principais participantes acabaram por beber de fontes internacionais, notadamente da cultura negra norte-americana, a fim de suprir uma "carência identitária", por meio de uma ação cultural que tinha como principais plataformas a conscientização étnica, resistência política e a oposição radical à democracia racial.

De certa forma, todos os textos valorizam, mesmo que percebendo algumas ambiguidades, uma nova produção cultural negra independente. Independência que logo se mostra contraditória, visto que desde o princípio da Black Rio havia conexões e relações estreitas entre esse circuito underground e o mainstream cultural carioca. Seja no trânsito de DJs entre bailes Zona Norte e boates da Zona Sul, seja no flerte inicial, e depois concretizado, com gravadoras multinacionais na produção e circulação de discos, e com a grande imprensa (mesmo que esta olhasse o movimento com desconfiança), o movimento sempre esteve em diálogo com instâncias da cultura mainstream da cidade.

Para aprofundar a discussão sobre as possibilidades de movimentações políticas em torno do consumo cultural, nosso objetivo neste artigo é demonstrar como o movimento Black Rio, fundamentalmente através do estabelecimento de redes de consumo, lazer e entretenimento guiadas pela música, configurou-se como uma cena musical que vinculou cidadania, estilo, linguagem e novas formas de apropriação de um espaço público. A Black Rio, ou Black Soul, mais do que um caráter meramente de resistência e oposição, propôs novas representações socioculturais e políticas através de práticas de consumo diferenciadas, marginais e, ao mesmo tempo, influenciadas por uma cultura de massa hegemônica. Foram ações complexas desencadeadas, em um primeiro momento, a partir da intensa atuação das equipes de som ou equipes de baile que organizaram as movimentações em torno dos grandes 
bailes black dos anos 70. Esses DJs e produtores se consideravam expoentes de um movimento de conscientização racial e cultural, agindo como receptores e retransmissores de uma cultura negra internacional. Essa visão, que cada vez mais influenciava suas ações culturais e práticas musicais, encorajava uma ampla adoção não apenas das sonoridades do soul, mas, em alguns casos, também do ethos dos movimentos negros norte-americanos, unidos em torno de uma causa comum, reproduzindo aqui lemas e ideias como black is beautiful, black power, power to the people, soul brothers. Sem abrir mão, no entanto, de uma proposta diferenciada de consumo cultural, em consonância com o desenvolvimento do mercado musical brasileiro e das transformações na cultura de massa internacional.

\section{O MERCADO DO SOUL}

A ditadura iniciou uma lenta abertura em meados dos anos 70, relaxando a censura e a tentativa de controle sobre reuniões e agrupamentos públicos, abrindo brechas para uma maior gama de expressões culturais em esferas públicas. Esse contexto refletia também um momento singular, baseado na crescente oferta de empregos que permitia a uma juventude negra periférica um maior poder de compra, inclusive de itens "supérfluos" como discos de vinil e roupas da moda. $\mathrm{O}$ crescimento desse novo segmento de mercado era resultado direto do chamado milagre econômico, promovido pelo governo militar, que rapidamente abriu o país ao capital internacional no começo dos anos 70 (o que não evitou a crise provocada pela dívida externa e a hiperinflação da década de 80, por falhas políticas e corrupção da ditadura). Mas, em curto prazo, o "milagre" aumentou a circulação de capital e possibilitou um maior poder de compra para vários grupos sociais pobres e marginalizados do país como, por exemplo, moradores dos subúrbios e periferias cariocas.

Além disso, a expansão dos meios de comunicação de massa incentivada, primeiro pelo governo modernizador de JK, e depois, pelo governo militar, contribuiu para a consolidação da indústria cultural no país. Isso que possibilitou, segundo Dias (2000, p. 40), a constituição de uma produção cultural internacional-popular, potencializada pelo sistema mundial de trocas simbólicas, e intensificada pelo processo de globalização, que favorecia a partilha de produtos, imagens, informações, hábitos e valores. DJs, frequentadores dos bailes e outros membros da cena black estavam prontos e abertos para transformar esse momento em uma oportunidade para a mobilização racial negra. A classe trabalhadora suburbana constituía-se como um espaço ideal para a emergência de uma espécie de movimento Black 
Power brasileiro, um grupo de indivíduos que representava um reservatório de descontentamento e de ambição por ascensão econômica e social. Assim, cada vez maiores e reunindo mais pessoas, os bailes black passaram a ser organizados em grandes quadras das escolas de samba do Rio, atraindo públicos de até 15 mil pessoas (ALBERTO, 2009, p. 13). Em meio a essas movimentações, a Black Rio mostrava sua face ambígua, pois, mesmo que os bailes black tenham criado um circuito paralelo de entretenimento negro na Zona Norte, eles foram particularmente felizes em invasões a espaços predominantemente brancos (inclusive haviam bailes fixos no Canecão e no Jardim Botânico), como o Museu de Arte Moderna, clubes de classe média da Zona Norte e discotecas da Zona Sul. Essas incursões em espaços da classe média poderiam inclusive ser facilmente percebidas como meras tentativas de ascensão social em um circuito mainstream, negando uma retórica oposicional mais forte e diluindo as especificidades que marcaram o começo do soul, como aponta McCann (2002).

Também as majors do disco, estações de rádio e emissoras de TV estavam ansiosas para lucrar com o potencial comercial do movimento soul, buscando garantir um lugar para o segmento no mercado musical nacional. A expansão do público na segunda metade dos anos 70 possibilitou às equipes de som e a seus produtores o aluguel de grandes espaços e o pagamento de anúncios nas rádios e jornais, o que angariou maiores vendas de discos e atingiu um público ainda maior. No princípio, gravadoras menores como a Top Tape e a Tapecar lançaram as primeiras coletâneas com repertórios dos hits mais tocados por equipes famosas como a Soul Grand Prix e a Dynamic Soul (BAHIANA, 1980, p. 218). Posteriormente, as afiliadas brasileiras da Polygram e Warner - que se tornaram as gravadoras mais poderosas do país, empurrando selos domésticos para as margens - beneficiadas pelo crescimento da popularidade da música americana no Brasil, passaram a lançar discos de soul de enorme sucesso, tanto de coletâneas de equipes quanto de novos cantores brasileiros do gênero. Esse êxito também acompanhava o aumento da popularidade da música americana vendida no Brasil por intermédio dessas gravadoras afiliadas locais. O maior poder econômico das multinacionais ainda garantiu uma maior distribuição de discos, bem como a compra de espaços publicitários na TV, e o soul entrou até nas trilhas sonoras de novelas e de programas musicais. As equipes também logo descobriram que um grande chamariz para o público era a incorporação de performances ao vivo aos bailes, organizando grandes shows que deram um especial incentivo aos cantores de soul brasileiros diante de uma audiência massiva. 
Críticos do movimento logo apontaram para o fato de seu caráter comercial e importado (ver FRIAS, 1976, BAHIANA, 1980, HANCHARD, 2001). "Adeptos do mito da democracia racial acusavam o movimento soul de importar o vírus perigoso da divisão biracial e animosidade norte-americana para um inadequado clima tropical" (McCANN, 2002, p. 35). Mesmo "esquerdistas" contrários à ideologia oficial encontraram muitos pontos para criticar o fenômeno do Soul pelo seu mercantilismo, seu estrangeirismo aparente e por utilizar, no lugar de uma instrumentalização política, uma abordagem "pop-cultural" no enfrentamento do racismo. Por um breve período, de 1975 a 1978, aproximadamente, essas críticas parecem não ter tido qualquer efeito e o soul espalhou-se do Rio para São Paulo e para a Bahia, além de outras cidades, incorporando inflexões locais à medida que se difundia.

Ao tentar-se compreender as dimensões da Black Rio, é fundamental perceber a articulação concreta e, por vezes, contraditória, dos vários estratos que compõem os processos culturais. Pois, como pontua Johnson (1999, p. 23), esses processos não devem ser vistos abstratamente e desvinculados das complexidades sociais que os produziram ou às quais eles se referiam originalmente. As práticas sociais e culturais devem ser examinadas com base em suas condições produtivas e estratégias discursivas de endereçamento, que incluem aspectos textuais, técnicos e também performáticos (tanto de seus artistas-criadores, quanto de mediadores e público), além de estratégias comunicacionais de reprodução e circulação (JANOTTI JR., 2006, p. 2). Ou seja, a Black Rio surge como uma resposta ao mercado, e dele ela não pode ser totalmente desvinculada em suas interpretações. Da mesma forma, sua articulação ao consumo não retira seu potencial político e subversivo, contido nos atos cotidianos, nas performances produzidas tanto nas pistas de dança quanto fora delas, e na configuração de espaços de lazer que também estabeleciam laços de solidariedade. É nesse ponto que o consumo pode ser visto como uma manifestação de sujeitos e identidades que interagem entre si em uma experiência coletiva de apropriação e uso de produtos culturais, conjuntamente a processos sociais que explicitam um "exercício refletido de cidadania", como defende Canclini em Consumidores e Cidadãos (2008, p. 89).

Alguns dos trabalhos interpretativos e analíticos anteriores a respeito do movimento Black Rio correm o risco de produzir visões redutoras ao enfocar, basicamente, suas articulações simbólicas e discursivas em relação a um processo de conscientização racial pautado pela cultura. E deixam de lado um olhar sobre as novas formas de produção, circulação e consumo desenvolvidas com base neste fenômeno cultural que, como qualquer outro processo cultural, foi marcado por complexidades e tensões. Se podemos compreender a 
cultura contemporânea como um conjunto móvel e dinâmico de processos políticos, sociais, simbólicos e econômicos, devemos partir do princípio de que os eventos culturais envolvem, ao mesmo tempo, dimensões simbólica, estética, social e econômica, manifestas tanto nos momentos de produção e circulação/transmissão, quanto na recepção, de acordo com as condições de reconhecimento e de consumo.

Ambiguidades que não retiram da Black Rio seu caráter de articulação política, construída por meio de vias alternativas para além dos exercícios políticos convencionais e seguindo outros direcionamentos que o simples caráter de "movimento de resistência racial". O ato do consumo é, aqui, dotado de sentido político, mas não necessariamente oposicional. E, ao não se levar em conta essa relação, pode-se perder de vista a complexidade das dimensões desse movimento enquanto fenômeno cultural, que deixou uma grande marca na cultura popular urbana do Rio de Janeiro dos anos 70, e um legado para expressões culturais subsequentes, como a criação do movimento charme e do funk carioca, também pautadas pela sobreposição de música, consumo e movimentação política, social e cultural.

\section{UM MOVIMENTO HETEROGÊNEO}

Uma segunda visão que marca algumas produções acadêmicas e também jornalísticas sobre a Black Rio considera o fenômeno como um momento da história cultural e social do negro brasileiro que seria "fortemente coeso a partir da criação de uma identidade coletiva", nas palavras de Rita Ribeiro no artigo Errância e exílio na soul music (2010, p. 167). Essa ideia confirma uma visão homogeneizante dos processos culturais, deixando de lado a noção de que a cultura é palco de conflitos e tensões em processos dinâmicos de legitimação e transformação. Ao analisarmos mais profundamente a atuação das equipes de som mais importantes do período, podemos perceber que, de forma alguma, existiam iguais preocupações e agendas políticas na pauta dos bailes organizados. Isso significa que os sentidos dos produtos culturais estão sempre em disputa, retrabalhando múltiplas identidades e articulando-se a questões mercadológicas, devendo, pois, ser repensados de formas mais sutis e complexas, evitando reduções.

Pela sua própria natureza como fenômeno de mercado, essas escolhas populares culturais eram, inevitavelmente, "impuras", e não eram inócuas às práticas capitalistas. O Movimento Black Rio trouxe altos ganhos financeiros tanto para negros quanto para brancos. O que contradiz a ideia de que "eram uma massa de jovens negros brasileiros criando seus 
próprios eventos culturais, completamente separados (pelo menos, aparentemente) das instituições da elite branca”, como interpreta McCann, (2002, p. 34). O que está se tentando demonstrar aqui é que, não há, de forma alguma, homogeneidade no movimento, em seus objetivos e finalidades. Assim, não é possível manter uma visão idílica e essencialista em torno dos processos de construção identitária. É importante levar em consideração a afirmação de diferentes e tensivos processos de identificação heterogêneos que, através da combinação de diversos elementos, gerou a constituição de novos estilos. Estilos estes que representavam uma síntese, no nível significativo, de diferentes formas de adaptação e negociação, mais do que atos de resistência étnica e racial.

Um exemplo da diversidade de ações e estratégias desenvolvidas nos bailes são as motivações das equipes de som. Por volta de 1976, as centenas de equipes de soul em atuação no Rio de Janeiro e em São Paulo davam corpo ao movimento Black Soul, que começava também a se espalhar por outros estados. Os DJs, usualmente, faziam parte de equipes que podiam contar com duas até dezenas de pessoas, dependendo do tamanho e importância do negócio. Além da produção do baile em si, as equipes eram responsáveis por transportar e instalar sistemas de som cada vez maiores e mais potentes, além de preparar a iluminação e a decoração do salão. Além de escolher e tocar o set list do baile, os DJs atuavam como animadores, realizando sorteios e concursos, criando diferentes atmosferas para os diferentes momentos do baile. Como mestres de cerimônia, muitos DJs iam além do papel de tocar discos e proferiam discursos inflamados e politizados em torno da conscientização racial, que davam o tom de bailes como os do Clube Renascença. Já em outras festas, o mote era a valorização e celebração de um estilo black, com premiações para melhores dançarinos e concursos de beleza específicos, que celebravam tanto uma estética afro-brasileira, quando um estilo baseado em um visual inspirado em celebridades afro-americanas (eram famosos os concursos que premiavam aqueles que se parecessem com os músicos Isaac Hayes e James Brown). Essas eram estratégias que buscavam uma conscientização racial tomando-se por base uma valorização estética e uma celebração de um estilo visual, mas também performático, em detrimento de uma atuação político-pedagógica mais convencional.

Houve ainda o caso de muitos DJs que buscavam apenas entreter suas audiências, animando seus bailes ao som do soul, em oposição às equipes que levantavam a bandeira do orgulho negro mais seriamente. Um exemplo foi a trajetória de Ademir Lemos, um DJ 
branco $^{2}$ que começou sua carreira no final dos anos 60, especializando-se em tocar rock and roll em boates da Zona Sul carioca. Ele fez sua transição para o soul em meados dos anos 70, com o objetivo de aproveitar o emergente mercado dos bailes black da Zona Norte. Por já possuir um maior capital para investir em aparelhagens de som importadas, e também tendo mais acesso aos últimos lançamentos da música negra norte-americana, sua equipe se tornou uma das mais bem-sucedidas do circuito do soul, cobrando em torno de mil dólares por um típico baile de final de semana (McCANN, 2002). Ademir Lemos também investia na área de produção fonográfica, um negócio até mais lucrativo do que a realização de bailes. Restrições de importação limitavam severamente a chegada ao mercado de discos brasileiro de selos norte-americanos independentes como Motown e Stax. Isso favorecia às majors com afiliadas brasileiras como a CBS e a Philips, dona da Polygram. Essa vantagem permitia que as multinacionais, ao lado de selos brasileiros regionais, adquirissem os direitos para distribuir singles americanos independentes no Brasil e também lançar coletâneas localmente. Lemos, assim, conseguiu negociar as marcas das mais importantes equipes de soul para as companhias de disco, que davam nome a coletâneas de sucesso, com as músicas mais tocadas nos seus bailes. E o público dos bailes de soul era um mercado garantido para esses álbuns, divulgados também por meio de estratégias de marketing preliminares como concursos e sorteios. Em meio a esse sucesso comercial, Lemos logo adotou a retórica do soul, com o discurso menos militante do "negro é lindo" (FRIAS, 1976, p. 5).

Ao mesmo tempo, o movimento também possibilitava a ascensão de jovens negros que começavam a abrir novas frentes de trabalho. Mr. Funky Santos, que se auto-intitulava o realizador da "primeira festa black, a primeira festa negra, 100\% negra nesse país" (MR. FUNKY SANTOS, 2007 apud RIBEIRO, 2010, p. 109) teve uma intensa atuação no mercado carioca da black music. Comandou programas em emissoras de rádio importantes como Imprensa FM, Roquete Pinto, Tropical e Manchete FM. E, com sua foto nas capas lançou, até os anos 80, uma série de cinco coletâneas em vinil dos hits de soul e funk que faziam sucesso em seus bailes. Na Top Tape, uma das mais importantes gravadoras cariocas nos anos 70 e 80, foi responsável também pela produção de dezenas de álbuns de outras equipes de som, como Black Power e Cash Box. Nascido no Morro da Mineira, localizado no Catumbi, bairro da Zona Norte carioca, o jovem Oséas Moura dos Santos trabalhava, no final dos anos 60, como

\footnotetext{
${ }^{2}$ Para Palombini (2009, p. 52), Ademir Lemos era mestiço, enquanto, segundo McCann (2002) ele era branco, o que pode denotar tensões nas apreensões e percepções sobre cor e raça entre observadores brasileiros (no caso, Palombini) e americanos (McCann), de acordo com as experiências culturais e raciais específicas de seus países.
} 
auxiliar de palco de grupos de rock. E começou a organizar pequenas festas informais, utilizando equipamentos de som simples e precários, mas já ostentando um cabelo "black". Em 1971, contando com apenas dois toca-discos, alguns amplificadores, seis caixas de som alugadas e iluminação deficiente (ESSINGER, 2005, p. 19), Oséas realizou seu primeiro baile black, tocando apenas soul music, ao qual compareceram 1500 pessoas. Essas experiências amadoras iniciais contribuíram para que o jovem DJ adotasse o nome artístico de Mr. Funky Santos e fundasse sua primeira equipe de baile, contribuindo para o embrião do movimento que posteriormente foi chamado de Black Rio.

Responsável por altos índices de vendas, o soul tornou-se um segmento rentável e lucrativo, influenciando culturalmente também comportamentos, estética e vestuário. A moda soul, principalmente aquela surgida no Rio de Janeiro, alternava-se entre a influência dos cantores e artistas negros dos EUA e a incorporação de elementos de uma estética africana em estampas, adereços e penteados. Recursos que auxiliavam na construção e difusão de um estilo e de uma ideologia política altamente influenciada pelo movimento negro americano e pelas lutas de independência das colônias africanas. Mas que também dava margens a questionamentos, como vemos em McCann:

O Movimento Black Rio foi, portanto, um fenômeno social nascido com uma luta pelo próprio significado em seu coração: seria um veículo da conscientização política negra, ou simplesmente mais um modismo pop enriquecendo produtores experientes? (2002, p. 49)

E, apesar do soul ter tomado de assalto a produção midiática massiva naquele período, incentivado por um contexto econômico que garantiu um progressivo aumento da oferta de emprego e renda, bem como um maior acesso ao mercado massivo da produção de bens culturais, o racismo estrutural era mantido. Mas a disponibilidade de mais informação e novas práticas de consumo favoreceram a criação de diferentes estratégias de luta e uma maior conscientização. Esses jovens negros passaram a exercer seu novo poder de compra enfatizando uma contestação da estrutura social e racial vigente com base em rituais simbólicos e práticas de consumo diferenciadas. Foi frequentando os espaços dos bailes que esse público ajudou a consolidar um estilo de se vestir e um código comportamental que mesclava as várias informações visuais que recebiam através de revistas, filmes, programas de TV e capas de discos. Essa busca por uma diferenciação a partir da escolha de determinados itens do vestuário (como sapatos de plataforma ou bicolores, calças boca de sino) e a utilização do cabelo natural, inspirado no visual dos integrantes do movimento Black Power 
norte-americano, demarcavam uma tentativa de incorporação de uma estética internacional por parte dos jovens frequentadores dos bailes, em sua maioria, de classes subalternas, conectados a uma cultura globalizada. E também representava uma possibilidade de articulação a um conjunto de símbolos marcadamente diaspóricos, como forma de diferenciação e dissenso em relação ao ambíguo mito da democracia racial. Esse novo estilo seria, assim, um reflexo do sentimento de esgotamento e de fracasso de uma perspectiva integracionista do negro na sociedade brasileira.

\section{CONSIDERAÇÕES SOBRE ESTILO}

No plano da vida cotidiana, o consumo organiza as sociedades e é moldado pela estrutura material e simbólica dos lugares, pelos modos de vida, pelas desigualdades, ideias e estilos, bem como pelas mudanças sociais (McCRACKEN, 2003). Ao pensar os intercâmbios globais na perspectiva da construção de novas formas de existência cultural, Canclini considera o consumo da música como uma fundamental e profícua maneira de expressar a cidadania e identidade, que podem se recompor em circuitos desiguais de produção, comunicação e apropriação cultural (2007, p. 137). Nesse sentido, o Movimento Black Rio pode ser compreendido como um exemplo de estratégia de reconversão cultural. Yúdice (2006, p. 183) considera que, mediante um sistema marcado pela globalização econômica e mundialização cultural, a reconversão cultural possibilita que os sujeitos desenvolvam novas práticas, habilidades e linguagens para sua reinserção em novas condições de produção, de consumo e de sociabilidade. Assim, as ações que caracterizaram o movimento não devem ser interpretadas apenas como atos de resistência racial. As nuances criativas e reconfigurações identitárias marcadas pelo consumo embasavam uma série de ações que sinalizavam o potencial provocador, subversivo e contraditório do Black Soul, que recortou e atravessou fronteiras de classe e raça.

Para Paulina Alberto (2009), a compreensão do sentido da Black Rio passa pelo intenso potencial transformador das políticas de estilo que o movimento propagou, engendradas pela conjunção de práticas de consumo cultural e demandas por modernas formas de cidadania (2009, p. 34). Essas estratégias significativas seriam alternativas a ações institucionalizadas promovidas diretamente por movimentos sociais e políticos, como o então Movimento Negro Unificado, organizado em 78, com uma pauta política concreta de 
enfrentamento ao regime militar ${ }^{3}$. Dados seus limitados recursos e fontes, os frequentadores e produtores dos bailes black produziam respostas mediadas que combinavam criatividade e consumo para configurar seu estilo, dramatizando, performatizando e construindo uma linguagem própria que marcava seus cotidianos com um explícito gesto político e significativo.

Os estilos construídos dentro e a partir dos bailes - o estilo dos blacks - eram superfícies da manifestação de tensões entre polaridades como subalternos x dominantes, negros x brancos, periferia x centro, tradição x modernidade, resistência x cooptação, que se alternavam em jogos reflexivos e complexos que representavam o embate e as contradições das partes fragmentadas da totalidade social. Os estilos, como práticas significantes e codificadas, são compostos por elementos como música, iconografia visual, performances, roupas, estéticas e sistema de valores (HEBDIDGE, 1979). E se tornavam indícios de um significado e de uma identidade em disputa, simbolizando, ao mesmo tempo, uma recusa a estereótipos e visões homogeneizantes, e também um desafio oblíquo a uma hegemonia e a uma cultura mainstream.

Essa comunidade simbólica de fãs, unida em torno do consumo de gêneros musicais, símbolos e objetos significativos nunca foi um conjunto uniforme. Ela sempre foi recortada por diferenças étnico-raciais e de classe, que não coincidiam integralmente nem formavam um todo homogêneo. Mas dividiam um mesmo tipo de linguagem e de práticas significativas, manifestas no estilo, no sentido dado por Hebdige (1979, p. 80), uma espécie de resposta mediada e codificada por transformações que estavam afetando toda a comunidade. Era no plano estético das roupas, danças, cortes de cabelo, na música, nos eventos de lazer que toda a retórica do estilo black estabelecia diálogos entre os processos alternativos de subjetivação e as condições de existência material.

Desta forma, catalisando uma política pautada pela afirmação de identidades, pela concretização de atos de consumo e performatização de estilos diferenciados, o circuito dos bailes black representava um contexto marcado pela recusa à perspectiva integracionista que fundou o mito da democracia racial, e também pela revolta em relação à precária situação do negro na sociedade brasileira. Neste sentido, o Movimento Black Rio pode ser compreendido

\footnotetext{
${ }^{3}$ A fundação do Movimento Negro Unificado (MNU), de orientação socialista, foi responsável por trazer de volta à cena política do Brasil um movimento negro organizado. Iniciativas esparsas e isoladas, constituídas ao longo do século XX em várias cidades do país, mais ligadas a redes assistencialistas, ações culturais e artísticas, e à criação de veículos de imprensa negra foram especialmente desmobilizadas pelo golpe de 1964. E só nos anos 70, algumas lideranças negras começaram a se rearticular, especialmente no Rio de Janeiro, São Paulo e Porto Alegre.
} 
como produto de novas estratégias interpretativas culturais e articulações identitárias por parte de grupos sociais marginalizados, mas que flertavam e se articulavam também com uma cultura mainstream, integrando-se à paisagem cultural carioca. Seu resgate histórico e compreensão a partir dos estilos desenvolvidos e de interações com a mídia popular massiva podem nos levar ao que entendemos por movimentações políticas através da cultura. Todas essas estratégias que entrelaçavam estética, performance, linguagem, sonoridades e discursos eram formas de negociação de posições, acionando novas representações e utilizando práticas alternativas de consumo cultural, que possibilitavam uma cidadania transversal e uma ação política da diferença, guiada por um viés estético na tentativa de transgredir fronteiras sociais e raciais.

Esperamos, com esse estudo, contribuir para a compreensão das práticas culturais contemporâneas afro-brasileiras no contexto urbano das grandes cidades, oferecendo uma possibilidade para a interpretação de diferentes exercícios de sociabilidade e experiências de solidariedade e entretenimento alternativos, que surgem das mesclas e hibridizações entre tradições brasileiras e produções globais. Nossa proposta é tentar lançar uma luz também sobre processos de consumo cultural e constituição de cenas musicais em torno da música popular massiva, a fim de compreender como populações marginalizadas interagem e transformam suas próprias culturas e existências sociais em ações descentralizadas e, em um primeiro momento, espontâneas, a fim de demarcar seus territórios significativos e garantir a construção de suas próprias cidadanias.

\section{REFERÊNCIAS}

ASSEF, C. Todo DJ já sambou: a história do disc-jóquei no Brasil. São Paulo: Conrad, 2003 .

ALBERTO, P. When Rio Was Black: Soul Music, National Culture, and the Politics of Racial Comparison in 1970s Brazil. Hispanic American Historical Review. Durham, Carolina do Norte: Duke University Press, 2009.

BAHIANA, A. M. Enlatando Black Rio. In: BAHIANA, A. M. (org.) Nada será como antes - MPB nos anos 70. Rio de Janeiro: Civilização Brasileira, 1980. p. 216-222.

CANCLINI, N. G. Consumidores e cidadãos. Rio de Janeiro: Ed. UFRJ, 2008. 
A globalização imaginada. São Paulo: Iluminuras, 2007.

CARDOSO FILHO, J. Poética da Música Underground: vestígios do Heavy Metal em Salvador. Rio de Janeiro: E-papers, 2008.

DIAS, M. T. Os donos da voz: indústria fonográfica brasileira e mundialização da cultura. São Paulo: Boitempo, 2000.

DOMINGUES, P. Movimento Negro Brasileiro: alguns apontamentos históricos. Tempo [online]. 2007, vol.12, n.23, pp. 100-122.

ESSINGER, S. Batidão: uma história do funk. Rio de Janeiro e São Paulo: Record, 2005.

FEATHERSTONE, M. Cultura de consumo e pós-modernismo. São Paulo: Nobel, 1995.

FERNANDES, N. O rapto ideológico da categoria subúrbio: Rio de Janeiro (1858-1945). 1996. Dissertação (Mestrado). PPGG-UFRJ. Rio de Janeiro.

FERREIRA, Marieta de Moraes (coord.). Rio de Janeiro: uma cidade na história. Rio de Janeiro: Editora FGV, 2000.

FREIRE FILHO, J.; FERNANDES, F. Jovens, espaço urbano e identidade: reflexões sobre o conceito de cena musical. In: FREIRE FILHO, J.; JANOTTI JÚNIOR, J. (org.).

Comunicação e Música Popular Massiva. Salvador: EDUFBA, 2006, p. 25-40.

FRIAS, L. Black Rio: o orgulho (importado) de ser negro no Brasil. Jornal do Brasil, Rio de Janeiro, 17 jul. 1976. Caderno B, p. 1 e 4-6.

FRY. P. Para inglês ver. Rio de Janeiro: Zahar, 1982.

GIACOMINI, S. A alma da festa: família, etnicidade e projetos num clube social da Zona Norte do Rio de Janeiro, o Renascença Clube. Belo Horizonte e Rio de Janeiro: UFMG e IUPERJ, 2006.

GILROY, P. O Atlântico Negro: modernidade e dupla consciência. São Paulo: Ed. 34; Rio de Janeiro: Universidade Candido Mendes, Centro de Estudos Afro-Asiáticos, 2001.

HANCHARD, M. G. Orfeu e o poder: movimento negro no Rio e São Paulo. Rio de Janeiro: UERJ, 2001.

HALL, S. Da diáspora: Identidades e mediações culturais. Belo Horizonte: Editora UFMG; Brasília: Representação da UNESCO no Brasil, 2003.

HEBDIGE, D. Subculture: The Meaning of Style. Florence, KY, USA: Routledge, 1979.

JANOTTI JR. Jeder Silveira. Por uma análise midiática da música popular massiva: uma proposição metodológica para a compreensão do entorno comunicacional, das condições de produção e reconhecimento dos gêneros musicais. E-Compós (Brasília), v. 1, 2006. 
JOHNSON, R. O que é, afinal, estudos culturais? Belo Horizonte: Autêntica, 1999.

MARTÍN-BARBERO, J. Dos meios às mediações: comunicação, cultura e hegemonia. 2. ed. Rio de Janeiro: Editora UFRJ, 2003.

McCANN, B. Black Pau: uncovering the history of Brazilian soul. Journal of Popular Music Studies, n. 14, p. 33-62, 2002.

McCRACKEN, G. Cultura e Consumo: novas abordagens ao caráter simbólico dos bens e das atividades de consumo. Rio de Janeiro: Mauad, 2003.

MOURA, R. A indústria cultura e o espetáculo-negócio no Rio de Janeiro. In: LOPES, Antonio Herculano (org.). Entre Europa e África: a invenção do carioca. Rio de Janeiro: Fundação Casa de Rui Barbosa, Topbooks, 2000. p. 113-154.

OLIVEIRA, L. X. Festas 100\% Soul: Os bailes do clube Astória e o movimento Black Rio. Anais do V Encontro de Pesquisadores em Comunicação e Música Popular (Musicom). Belém-PA, v. 5, p. 1-11, ago. 2013. Disponível em: < http://musica.ufma.br/musicom/trab/2013_GT3_03.pdf>. Acesso em: 09 fev. 2015.

ORTIZ, R. A moderna tradição nacional. São Paulo: Brasiliense, 2001.

PALOMBINI, C. Soul brasileiro e funk carioca, Opus, v. 1, n.15, p. 37-61, 2009.

RIBEIRO, R. A. C. Errância e exílio na soul music: do movimento Black Rio nos anos 70 ao Quarteirão do Soul em Belo Horizonte, 2010. Tempo e Argumento, Florianópolis, v. 2, n. 2, p. 154-180, 2010.

RISÉRIO, A. Carnaval Ijexá: notas sobre afoxés e blocos do novo carnaval afrobaiano. Salvador: Corrupio, 1981.

STRAW, W. Systems of articulation, logics of change: scenes and communities in popular music. Cultural Studies, v. 05, n. 03, p. 361 - 375, Oct. 1991.

THAYER, A. Black Rio - Brazilian Soul and DJ Culture's Lost Chapter. Wax Poetics, New York, n. 16, p. 88-106, abr./mai. 2006.

VIANNA, H. O mundo funk carioca. 2.ed. Rio de Janeiro: Jorge Zahar Editor, 1997.

ZAN, J. R. Jazz, soul e funk na terra do samba: a sonoridade da banda Black Rio. ArtCultura, v. 7, n. 11, p. 187-200, 2007.

YÚDICE, G. A Conveniência da Cultura. Belo Horizonte: Editora UFMG, 2006. 
Original recebido em: 03/04/2015

Aceito para publicação em: 29/07/2015
Luciana Xavier de Oliveira Doutoranda do Programa de PósGraduação em Comunicação da Universidade Federal Fluminense 